\title{
DIGITAL COMPETENCE IMPROVEMENT BY LITHUANIAN SCHOOL TEACHERS DURING COVID-19
}

\author{
Estela Daukšienè, Elena Trepulè, Airina Volungevičienè, Vytautas Magnus University, \\ Lithuania
}

\section{Abstract}

Distance teaching and learning in Lithuanian schools during COVID-19 pandemic was a booster for teacher digital competence development. The paper analysis the experiences of Lithuanian school teachers to reveal the challenges schools and teachers faced while switching from traditional face to face teaching and learning to distance education. The research revealed existence of different level teacher digital competences at a school and uneven competence development in each school. The analysis of experiences of Lithuanian school teachers through the lens of DigCompEdu framework revealed that professional development competence was the background for other competence areas to develop. The need for digital resources for teaching online contributed to the teacher digital competence development of this area. Digital assessment was indicated as the main challenge that remained unsolved in many cases. Research found that technological peculiarities were easier to learn and showed the need to develop teacher social and didactical competences which are necessary for distance teaching. Lack of activities to empower learners and develop their digital competences was recorded. Teachers themselves acknowledged great improvement of their digital competence.

\section{Introduction}

All teachers know the potential of using technologies for teaching and learning, however until the need comes only some of them find time to learn how to use new technologies and use them for teaching and learning. Teacher digital competence development has been the focus for a long time, however the lockdown situation due to the COVID-19 pandemic initiated different needs and approaches. With the need to social distancing and staying at home came the necessity to organize distance teaching and learning for schools, which used to organize learning face-to-face. Were they prepared for that? How this challenged them and contributed to their digital competence? 
The digital competence is usually understood as an ability to use technologies for different activities and depending on the selected framework may have different elements or stress the use of technologies for different activities and in different areas. The most popular framework to define digital competences in Europe is the DigComp framework (Digital Competence Framework for Citizens) which was introduced in 2013 (Ferrari, 2013) and updated in 2016 (Vuorikari et al., 2016) and 2017 (Carretero Gomez et al., 2017). Some countries (such as Spain) have adapted and applied this framework for defining and developing teacher digital competence; they link the 5 digital competence areas indicated in the framework, to the courses or in service training programmes that are provided for teachers.

The recent European Framework for the Digital Competence of Educators DigCompEdu (Redecker, 2017) was developed in 2017. It is broadly used and applied in Europe as the core resource, defining teacher digital competences. DigCompEdu framework defines 3 blocks and 6 areas of teacher digital competence: (a) educator's professional competences - professional engagement; (b) educators pedagogical competences - digital resources, teaching and learning, assessment, and empowering learners; and (c) learners competences - facilitating learners' digital competence. In all these competencies a teacher needs to use technologies for different activities to be competent. This paper aims to analyse the experiences of Lithuanian school teachers while teaching online during COVID-19 pandemic first wave (March-October 2020) with the focus to reveal the development of teacher digital competence in all 6 areas of DigCompEdu framework.

\section{Methodology and background}

Before March 16th, 2020 when all Lithuanian schools were closed due to the spread of COVID-19 pandemic, only several Lithuanian schools had a possibility to organize distance teaching and learning. There existed regulation for a school to receive the approval from the Lithuanian Ministry of Science and Education to organize distance teaching and learning. The created limitation led to the situation that there were only several schools in the country which had part of their school learners or just some subjects taught online. Thus, a very small number of teachers had experience in teaching online before COVID-19, and the need to organize distance teaching and learning for a traditional school was a real challenge.

In March 2020, when the pandemic stopped the regular processes globally, in Lithuania all schools were closed for two weeks to prepare for teaching online. During those two weeks a school had to agree on how the process would be organized, what tools to be used, what schedule to follow, what devices and internet connection pupils and teachers had and which were possible to be used, and much more to agree upon to start distance teaching at 
the end of March. It was a tough period for all - school administration, teachers, IT specialists, etc. During those two weeks there were lots of webinars organized nationally for school representatives by universities, politicians and those who could provide some guidance either for teachers or school leaders, however having no experience it was difficult to plan. Thus this leads to many different scenarios and experiences.

To reveal the experiences of the Lithuanian school communities the qualitative research approach was selected. Two research data collection methods were applied: expert interviews with school administration representatives were organized to reveal the experiences of school leaders; and focus groups with teachers, with upper grade pupils and with parents of lower grade pupils were organized to reveal the experiences of different participants of learning process. The targeted convenient selection of participants created a possibility to choose the most proper research sample (Rutkienė \& Tandzegolskiené, 2013; Žydžiūnaitė \& Sabaliauskas, 2017) for the empirical research. For the selection of schools to participate in the research the following selection criteria were indicated: different technological scenarios and platforms (focusing on selecting schools with different chosen technological scenarios), different school experience in organizing distance teaching and learning; different type of schools (ensuring the variety to be represented - from primary to upper secondary); different Lithuanian region (to include bigger and smaller towns and rural areas).

Eight Lithuanians schools were selected according to the selected and described criteria. There were eight expert interviews with the representatives from administration of the selected Lithuanian schools; the person had to have a leading role in managing distance learning at school. There were five focus groups with teachers (8-9 teachers each) organized. They were participated by 41 teacher of different subjects - Lithuanian language and literature (7), history/geography (5), Math (4), chemistry (3), English language (3), Music (3), and other. The age of teachers ranged from 22 to 69 . There were two focus groups with upper grade secondary school pupils (8-9 pupils each) and two focus groups with parents of lower grade pupils (6-7 parents each, half of the parents had more than one child of school age). Most parents were of age 30-49, and all pupils were from 16 to 18 years old (there were 30 parents and pupils in total). The empirical research was conducted in September-October 2020 to reveal the experiences of the first pandemic wave in MarchJune 2020 and the preparation steps (September-October) for the second wave which started in October-November 2020 (depending on the situation in the regions).

The participants of expert interviews (school administration representatives) were coded as A1, A2, A3, etc., while participants of focus groups were coded with 2 letters and 2 numbers, indicating the research method (F for Focus group), the number of the school, the target group participant ( $\mathrm{T}$ for teacher, $\mathrm{P}$ for parent and $\mathrm{S}$ for pupil/student) and 
number of the participant in the group, such as F1T2 stands for a focus group organized in school No.1, Teacher No. 2, F2S4 stands for the school No.2 student(pupil) No.4, and F4P3 stands for the school No.4 parent No.3.

Qualitative data of the expert interviews and focus groups were analysed through thematic analysis, based on the steps which include several phases indicated by the researchers (Braun \& Clark, 2006; Clark \& Braun, 2013; Nowell et al., 2017). It was started with familiarization with the collected data; was followed by generation of initial codes, search for, review and naming of the themes; and finalized with the production of the report. To ensure the privacy of data and research participants the following research principles of ethics (Žydžiūnaitė \& Sabaliauskas, 2017) were followed in all research stages: respect to persons (research participants were coded) and their privacy (research participants were not fostered to reveal more than they openly shared), confidentiality and anonymity (all details that might reveal participant identity or school were anonymized, the researched schools were known only to the research team), beneficence and non-maleficence (time for interview and focus group were adapted to participant preferences, also following the same principle in agreeing if the meeting was to be held face-to-face or virtual; negative ideas and approaches that were identified during research were impersonalized), and justice (research participants agreed to participate in the research; an obligation to provide correct statements by research participants were followed).

\section{Research results}

The thematic map of the themes identified from all research participants are presented in Figure 1. The discussion of research results is followed by the different themes from the thematic map.

The analysis of research data revealed that possession of teacher digital competencies varied not only between schools and different subject teachers, but also there were huge differences on the level of digital teacher competencies in the same school. Some teachers lacked digital competences [A5, F4P6], didn't know how to use videoconferencing tools [F4P6, F3P1] or

"were afraid to click anything not to destroy the devices" (A2). 


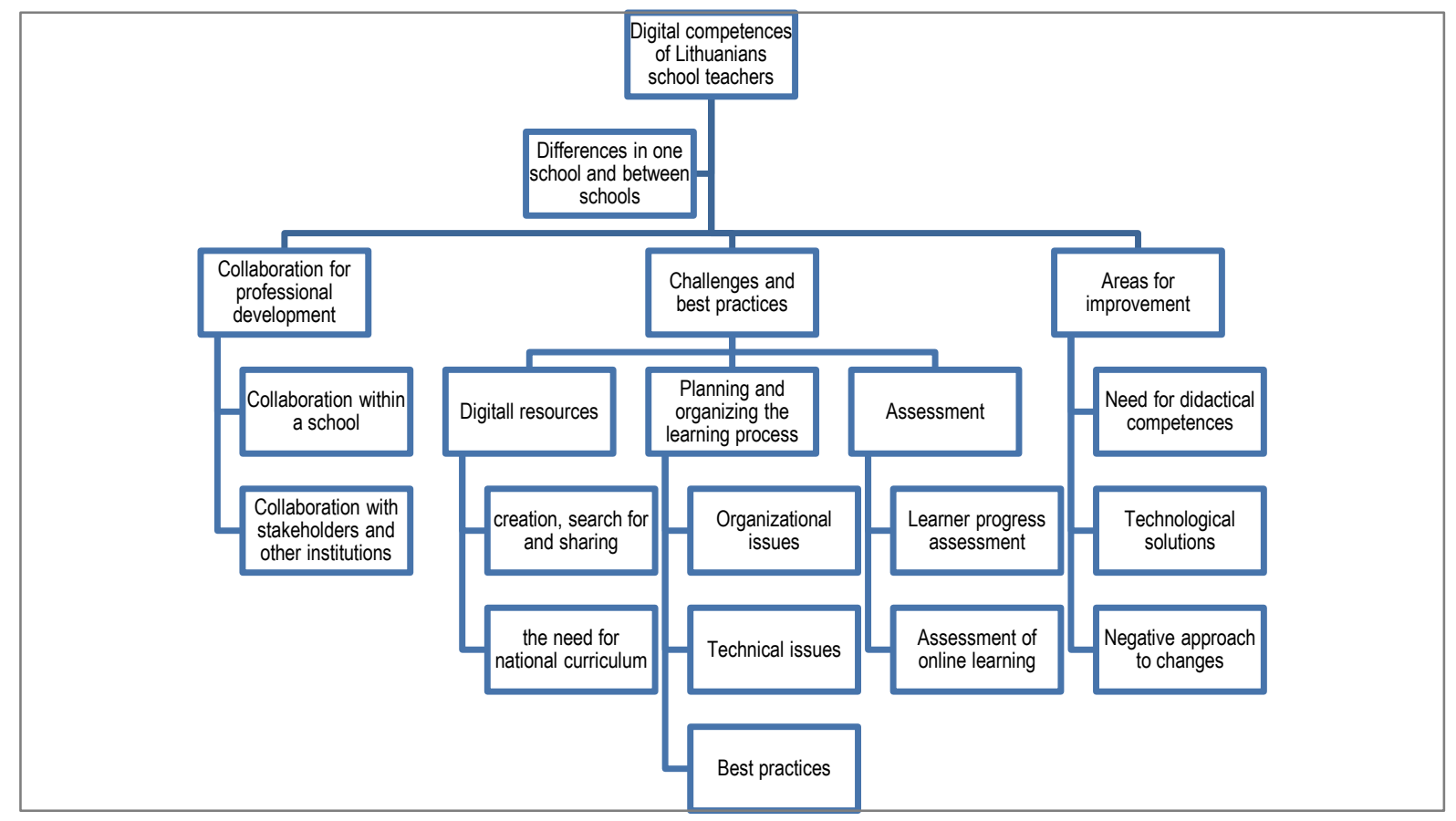

Figure 1. The thematic map of digital competence development of Lithuanian school teachers during the first wave of COVID-19 (March-October, 2020)

There were some schools which were satisfied if the teachers somehow connect to synchronous video lessons [A4, A6] and use videoconferencing tools to provide assignments for pupils [A2, A5] or organize synchronous lessons [A6, A7], while there were some schools where the quality of distance learning was the focus from the very start [A8]. The schools which organized distance learning earlier [A8] or had some teachers with advanced digital competences before pandemic [A1, A2, A5, A7] were able to come up to creative solutions [F2M5, A7] or organize teacher to teacher consultations [A1, A2, A7]. There were teacher methodical groups created for teacher collaborations [A1, A2, A8] in some schools; younger teachers or social staff were assigned to the teachers who lacked experience or knowledge in technology use in other schools [A7].

\section{Collaboration for professional development}

The deteriorating epidemiological situation and the overarching challenge of bringing the educational process to the digital space have brought many teachers closer together, enabling intensive professional collaboration between members of the school community [A1, A2, A,3 A7, F2T8]. The latter remains one of the positive effects of quarantine: professional cooperation between teachers in methodological groups has even strengthened and increased [F1T5, F2T3, F2T8].

To maintain a sense of community and encourage teacher collaboration, schools have developed: a virtual "coffee break" [A1, A2], a collaboration activity called "boss hour" [A1], or a "virtual teacher room" [F1T5], where teachers met remotely every morning, and the administration not only used the possibility to discuss current issues, but also 
supported or encouraged each other psychologically [A7]. School community collaborated and helped each other in this non-traditional situation:

"pupils helped teachers, pupils helped pupils" (A5)

"pupils also helped each other" (A3)

Collaboration with parents usually were organized by class mistresses [F3P2, F4P6, F3P1], who organized meetings with parents remotely. The attendance of parents at the remote meetings was significantly higher than at regular school meetings [A3, A6, F1T5].

Although there were many meetings and events, the school leaders emphasize that they lacked productive cooperation with the representatives of the Ministry of Education, Science and Sport (further Ministry) and a clearer strategy and focus for the implementation of distance learning [A1, A2, A3, A5]:

"we were expecting more guidance and clear proposals from the Ministry and the municipality, e.g. when selecting tools. What we have received cannot be called even guidelines, just a patchwork of existing opportunities, which can be found on the Internet" (A1).

Cooperation between school leaders and the municipality has in many cases taken place using video conferencing tools [A1, A2, A3, A4, A5] or social networking facilities [A4]. Some school leaders were very pleased with the productive collaboration with the municipality (school stakeholders) and the fact that the collaboration continued [A2], but in some schools the collaboration of school leaders and municipalities was idle [A6].

\section{Challenges and best practices: Digital resources}

The analysis of the research data revealed that all schools organizing teaching and learning during pandemic used both - digital learning content F3P2] in combination with traditional textbooks [F1M, F4T3, F4T5]:

"yes, we used digital resources and teachers shared places where to find this kind of material" (A6)

"we used mixed content" (A3)

Teachers created digital content themselves [A7, F4T8], shared and used their developed learning content or open educational resources [A1, F5T1, F5T2] and other types of open digital content:

"we used online digital lessons that were found on internet and were available" (A2) 
This was the commercial learning content which was temporarily made open in many cases [A3, A8, A6, A7, A2]. Research participants mentioned an unequal amount of prepared and appropriate digital content for different subjects, different subject topics [A3, F5T1], and the absence of digital content for some subjects:

"There have certainly been subjects where there was no digital content, or there existed but much less than teachers needed" (A5)

The lack of nationally developed digital content was stressed [F1P3]. The later might be used by all schools when the need to organized distance learning arises:

"Digital content should be freely available to schools, freely, it should not be commercialized" (A2)

It was emphasized that there is no common strategy [A3, A5] and that schools should have access to digital learning content on a shared platform [A3]. Digital content - theory and complementary exercises or tasks [F5P1, F2P2] are necessary, and they should encourage students' creativity and active learning, and not just answering of multiple choice questions [A3].

\section{Challenges and best practices. Teaching, learning, and assessment}

The organization of distance education was chaotic, the question was raised about what can be called a quality lesson in distance learning [A8]. It was acknowledged that not all the possibilities of the chosen platforms were used, because teachers simply did not know them and therefore applied small variety of methods, limiting group learning [A8], or active online learning F2S7]. The tasks mostly were performed on paper and a photo of them was sent via different channels - email [F2T5], messenger [F2T4] or online grading book [F4T2] - which were not always appropriate for big volume files so creating challenges to open some documents [A5]. Incompatibility of equipment has also contributed to the chaos of online learning as pupils used different devices - tabs, phones, or computers.

Some schools used Moodle [F2P6] or MsTeams [A1] for learning management. However, there were some schools which let teachers choose and use what they know [A4]. Thus, teachers used a variety of tools [F2M5, F2M1, F2M4, F2M8, F2P1, F3P2, F4P4, F2P1]. Not only the variety of technologies, but also the variety of teaching strategies used existed in one school leading to challenges for pupils:

"five teachers do things differently - the tasks can be found anywhere. Thus, in the beginning the challenge was to understand the teacher strategy, the rules, the tactics, how he teaches" (FIM8) 
Lack of technological knowledge and instructions on how to use technologies lead to the lesson with 200 participants instead of one class pupils joining a lesson [A2]. The need for clear instructions [A1, F3T4] and coherent planning [F5T4] were indicated by different research participants, where the lesson plans that were prepared and shared with learners in advance were mentioned as the main success factors [F2S5, F2T5]. The need for tasks, which help pupils plan their time and learn independently, were also stressed [F1T1, F2T6]

Assessment was indicated as a biggest challenge [A1, A2, A7, F4P6, F2P5] that was not solved by some subject teachers [A1, A2, A7]. Teachers didn't know technological solutions for creating online tests or such tasks that would not lead to cheating. However, they used technologies for self-check activities or applied various methods for collecting feedback from learners regarding distance learning process. The preparation for these activities were very time consuming, leading to many teachers working unlimited number of hours [A6, F4T8].

\section{Areas for improvement. Teacher didactical competences to engage learners and improve their digital competences}

The analysis of data revealed the need for digital didactical competences. It was easier to learn some technical or technological peculiarities, to use technologies, but it was more difficult to teach online, to organize the distance learning process. In the beginning most teachers tried the same teaching and learning methods and approaches that they use to implement in face to face classes [A4];

teachers "turned on video cameras and worked the same way they used to work at school, just in video lessons ... synchronously ..." (A2)

However later came the feeling that it was not enough to do the same things that were done in the classes to reach better results [A8]. And even after several months online it was indicated that

"not all teachers found the methods that work" (A2)

The questions regarding the principles of time management during online lesson were raised [F4P6, F3P1], the need for more teacher social skills, for new ways of communication online were stressed [A1, A2, A7]. Not all teachers had a positive approach to changes that were initiated due to pandemic. Thus, there were some teachers who left the school after the first months of teaching online. The reasons for leaving were several unwillingness to apply technologies for teaching or to improve digital competences and change practices that they used to apply [F4P3, A2], or internal limitations and protest [A5, A7, A8]. Some teachers denied the existence of COVID-19 stressing that online learning will disappear [A7]. 
Research shows that many teachers had a possibility to start using the tools that earlier they never found time for start using, and this lead to advanced teacher digital competences: [F1P2, F2P1, F1P8, F1P3, F5P5, F2P2, F5P2, F5P1, F2M5, F3T6, A3, A4, A5]:

"we've learnt a lot of things, in deed" (F3P3)

"we learnt what we never knew of existing. We see how it is useful" (F3P8)

However the activities organized by teachers while teaching online have not focused on engaging learners, nor improving their digital competences. But summing up their digital competence improvement teachers acknowledge:

"Let's be open and sincerely say: Thank you, Corona, for forcing us to improve, greatly" (A4)

\section{Conclusions}

The research showed that the digital competences of Lithuanian school teachers varied in the same school from those who were basic users to advanced ones. This created a place for teacher collaboration for a learning process to be implemented successfully methodological groups of teachers collaborated on certain subject teaching peculiarities, younger and more advanced teachers and specialists helped those who lacked digital knowledge and skills; good practice sharing webinars were organized to share what works. Different situations were recorded analysing the use of digital content for teaching and learning online, as different subject teachers faced different challenges in finding or creating the curriculum themselves. Teacher cooperation was recorded in this area as well. Distance teaching revealed the need for teacher social and didactical competence development, as technical peculiarities were easier to learn. Some good practices in applying different learning methods were recorded, however tasks that would improve pupils' digital competences were not recorded. Learner assessment was indicated as the main remaining issue. Pupils called for more interactivity, confirming the need for teacher digital didactical competence development.

"Real change often takes place in deep crises, and this moment holds the possibility that we won't return to the status quo when things return to 'normal'" (Schleicher, 2020; p.26). This idea may also be supported by Lithuanian teachers' thoughts that they were forced to try technologies for learning, but this revealed a number of possibilities to be used in future. 


\section{References}

Braun, V., \& Clarke, V. (2006). Using thematic analysis in psychology. Qualitative Research in Psychology, 3, 77-101. https://doi.org/10.1191/1478088706qp063oa

Ferrari, A. (2013). DIGCOMP: A Framework for Developing and Understanding Digital Competence in Europe. In Y. Punie \& B. Brecko (Eds.), EUR 26035. Luxembourg: Publications Office of the European Union. http://dx.doi.org/10.2788/52966

Carretero Gomez, S., Vuorikari, R., \& Punie, Y. (2017). DigComp 2.1: The Digital Competence Framework for Citizens with eight proficiency levels and examples of use. EUR 28558 EN. Luxembourg: Publications Office of the European Union. http://dx.doi.org/10.2760/38842

Clarke, V., \& Braun, V. (2013). Teaching thematic analysis: Overcoming challenges and developing strategies for effective learning. The Psychologist, 26(2), 120-123. http://dx.doi.org/10.1191/1478088706qp063oa

Nowell, L. S., Norris, J. M., White, D. E., \& Moules, N. J. (2017). Thematic Analysis. Striving to Meet the Trustworthiness Criteria. International Journal of Qualitative Methods, 16, 1-13, http://dx.doi.org/10.1177/1609406917733847

Redecker, C. (2019). European Framework for the Digital Competence of Educators: DigCompEdu. In Y. Punie (Ed.), EUR 28775 EN. Luxembourg: Publications Office of the European Union. http://dx.doi.org/10.2760/178382

Rutkienè, A. \& Tandzengolskienè, I. (2013). Gebejjimo veikti savarankiškai raiška universitetinių studijų metu (socialinių mokslų srities atvejis). Acta Paedagogica Vilnensia, 31, 69-83. https://doi.org/10.15388/ActPaed.2013.31.2514

Schleicher, A. (2020). The impact of COVID-19 on Education - Insights from Education at a Glance 2020. Retrieve https://www.oecd.org/education/the-impact-of-covid-19-oneducation-insights-education-at-a-glance-2020.pdf

Vuorikari, R., Punie, Y., Carretero Gomez, S., \& van den Brande, G. (2016). DigComp 2.0: The Digital Competence Framework for Citizens. Update Phase 1: the Conceptual Reference Model. EUR 27948 EN. Luxembourg: Publications Office of the European Union. http://dx.doi.org/10.2791/607218

Žydžiūnaitė, V., \& Sabaliauskas, S. (2017). Kokybiniai tyrimai principai ir metodai. Vilnius: Vaga. 